a state of repair made the author wish that the native chauffeurs supported their faith and hope by good works, nor that he evidently cherishes a sympathy with Stevenson's dictum that it is better to travel hopefully than to arrive.

We have here, in fact, diversified fare with something to suit most tastes, and if the narrative is at times inconsequent, it is at once easy to relinquish but pleasant to resume. The text is illustrated by a number of excellent photographs, the large majority of a botanical character.

E. J. SALISBURY

\section{ORIGIN AND USE OF ATOMIC ENERGY}

\section{Sourcebook on Atomic Energy}

By Samuel Glasstone. $\mathrm{Pp} . \mathrm{v}+546$. (London : Macmillan and Co., Ltd., 1950.) 24s. net.

$\mathrm{T}$ is a real pleasure to be able to say that $\mathrm{Dr}$. 1 Glasstone's book on nuclear physics is excellent. It is an account, practically without mathematics, of what we call nowadays 'nuclear physics', with a few extras thrown in. What are its merits? It is com plete, with, of course, the exception of the nondescriptive parts of theory. It is eminently readable : the fascinating description of the discovery of fission or the recognition of the neutron in the world are little masterpieces. The author, particularly when discoveries are described, often quotes the original text, which makes it all the more exciting. The book is very up to date (with a slight reservation in the section on cosmic rays) for a tome of more than 500 pages. Berkelium and californium (March 1950) are included, and a real attempt is made to be fair historically, a particular achievement in a field where national ambitions are not always absent. The book is astonishingly free from mistakes.

The first twelve chapters deal with nuclear physics such as radioactivity, accelerators, isotopes and their separation, transmutations, the neutron, nuclear forces and the structure of nuclei. The thirteenth and fourteenth deal with fission and the utilization of nuclear energy, followed by an excellent section on the transuranic elements (neptunium, plutonium, americium, curium, berkelium, californium) and the new elements technetium (43), promethium (61), astatine (85). The article on the uses of isotopes forms chapter 16, and includes labelling of compounds, with selected examples discussed in detail, the application of isotopic tracers in biology, agriculture, industry, chemical analysis, and the beautiful work of W. F. Libby using carbon-14 as an archæological 'clock', Cosmic rays and mesons are studied in chapter 17. The final, but not least important, chapter deals with health physics, covering such items as radiation meters, radiation dose, remote handling, shielding and the genetic effects of radiations. An author and subject index complete the volume.

The book will obviously appeal to a wide range of readers. Most of it can be read by anyone with a good secondary school education. It should appeal particularly to the medical practitioner and the school science teacher, the student, and anybody who prefers a lively, well-written professional account of the subject-matter to one of the glamorous phantasies which occasionally appear on the market.

The printing is well done, but the photographs are not well reproduced.
The book is sponsored by the United States Atomic Energy Commission and is sent on its way with a foreword by G. Dean, chairman of the Commission. It is good value for the money.

E. Bretscher

\section{SOURCE-BOOK OF DATA FOR NUCLEAR PHYSICS}

\section{Nuclear Data}

A Collection of Experimental Values of Half-Lives, Radiation Energies, Relative Isotopic Abundances, Nuclear Moments and Cross Sections. Compiled by Katharine Way, Lilla Fano, Millicent R. Scott and Karin Thew. (United States Department of Commerce : National Bureau of Standards, Circular 499.) Pp. xiv +309 . (Washington, D.C.: Government Printing Office, 1950.) 4.25 dollars + postage; this includes cost of three supplements to be issued halfyearly.

THIS detailed and massive tabulation is intended

for critical reference rather than for rapid general survey : it fulfils its purpose admirably. About 1,200 isotopes are known at present, and the editors have allocated ample space to describe each one. They were thereby enabled to make their table much more lucid and detailed than previous compilations of this sort. It contains a lot of information not previously tabulated, and a widespread use of level-diagrams aids comprehension of complex decay schemes. Particularly noteworthy are the internal-conversion ratios of gamma-transitions and an impressive assembly of nuclear cross-sections; the table does not, however, list exact atomic masses. Bibliographic references are given for all the data, and even the reference keys inform by revealing the year of publication. Much of the new information contained in this book comes from American reports which, though available to the public, are not yet readily obtained in Great Britain.

Isotope charts and tables have a habit of drifting out of date, shortly after release, on the swelling flood of new information. This comprehensive new table takes us to the end of 1949 with a peep into 1950 , and perhaps its greatest virtue is the specific contract to provide supplements of new data at half-yearly intervals. The table has been designed to allow the assimilation of supplements in loose-leaf form. The present binding is too flimsy to survive much handling, and one wishes that the National Bureau of Standards had made a suitable loose-leaf cover available: it seems, however, that the lefthand margin may prove too narrow, so that the book will not open sufficiently.

Some of the abbreviations used seem unnecessarily cryptic. I regret also the authors' decision not to indicate the reliability of chemical and mass assignments; it is true, as they say, that occasionally assignments assessed as 'certain' have proved false; if one accepts that pretext, much other information should be eliminated from the table. The assessments published previously were the fruits of much careful thought and, with a slightly more stringent use of the $A$-grading, would be sufficiently reliable.

These are minor criticisms; I have no doubt that this work will become a standard authority for nuclear information.

\section{J. S. STORY}

